\title{
Impact of Global Crisis in Present Scenario: A Practical Study of Corporate Recruitment and Selection Process in India.
}

\author{
Madhavaiah Upati \\ (Asst. Professor of English, (PAT) Vardhaman College of Engineering, Hyderabad, A. P, India
}

\begin{abstract}
It is evidently clear that Indian corporate industry has gone through several stages like production centric, service centric and now employee centric which may not be the same in future. It has also been experiencing several changes in terms of pooling the right talent. It need further required skill set in order to achieve efficient and effective operations to perform the assigned task skillfully. Apparently, this is how the role of H.R Department has become highly pivotal in business organizations run by effectively and mind mapping the skills and aspirations of the employees.

Having identified and getting experienced with current recruitment and selecting process, this paper throws a light on Indian corporate industry at present. However, strategies and approaches in attracting the right talent and the ongoing processes of recruitment and selection coupled with retaining strategies.
\end{abstract}

Key Words: Employee Centric, Pool, Right Talent, Efficient, Pivotal, Strategies \& Retaining.

\section{INTRODUCTION}

Post recession corporate market is in its own need of potential talent acquisition. As most of the employers are able to realize the importance of human capital in order to meet departmental \& organizational objectives and also align the future business strategies.

Over a period of time, there has been a drift in candidate's expectations as well as employers expectations. Keeping these expectations and constant changes in mind H.R professionals have to have strategic plans and approaches to attract, hire and retain the right talent that contributes the optimal and get adapted to the organizational culture. Trends, Approaches, expected skills set from the participants, changing patterns in hiring process and recommendations in the Present recruitment selection process would be discussed in detailed.

\section{WHAT IS RECESSION?}

A Recession is a contraction phase of the business cycle.

NBER (National Bureau of Economic Research) is the official agency in charge of declaring that the economy is in a state of Recession.

It defines Recession as: "Significant decline in economic activity lasting more than a few months, which is normally visible in real G.D.P. real income, employment, industrial production and wholesale-retail sales".

\section{A GLANCE ON RECESSION IN US}

Because of major crisis faced by US (sub prime mortgages prices, high unemployment rates and decline in dollar value, etc) low down the growth of the economy and G.D.P. growth rate fell to $2 \%$ and thus recession set in.

In September (2008) 1, 59,000 jobs lost and there was 10.9\% unemployment in US.

Lehman brothers being the largest bankruptcy in US history makes 2008 a record year in terms of assets. As a result India's export growth turned as negative and fell sharply.

In India though the rupee has positive impact on import but has negative impact on export and FDIs.

Above all, in India almost all the citizens are prudent in their consumption, coupled with the great contribution of lady domestic savings has made our G.D.P. to be stable.

I feel, the fear of Recession to be a continuous and long lasting process had a severe economic downturn, in real sense Recession generally lasts for two quarters.

News papers, researches and corporate market expose the global economic recession has taken its toll on the Indian economy that has led to multi-core loss in business and export orders, thousands of job losses, especially in key sectors like IT, ITEs, automobiles, industry and export-oriented firms. And have got a sense of feeling that recession has also shaken up the investment arena that leads to a difficult phase for a growing economy like India. 
Indeed, India as the most dependent on agricultural sector (The Recession had no much impact on this sector) it could somehow uphold itself from the affect of global Recession.

\section{RECRUITMENT VS. SELECTION}

Recruitment and selection is the spine of an effective and productive human capital for an organization.

Recruitment is the process of finding potential candidates for a job, while selection is the process of selecting the right person for the right job and a process of matching the organizational requirements with the skills, abilities and qualifications of the candidate in order to achieve efficient and effective operations.

Mr. Nirmal Singh, cofounder \&CEO of WHEEBOX, says that Recruitment is a positive process while selection is a negative approach where the focus is on eliminating the candidates from the gathered talent pool.

\section{CURRENT TRENDS IN RECRUITMENT}

Most of the recruiters feel that the bellow trends are not only cost effective but also save time and resources.

$\checkmark \quad$ Job portals

$\checkmark \quad$ Social media platforms (Face book, Twitter, etc)

$\checkmark \quad$ Employee references

$\checkmark \quad$ Mapping

$\checkmark \quad$ Headhunting

$\checkmark \quad$ Consultancies

$\checkmark \quad$ E-Communities

$\checkmark \quad$ Job postings on sites

$\checkmark \quad$ Mass mailings

Internal Database

Over the years, the recruitment industry has also witnessed a change in hiring trends and assessment techniques. Now, the focus is on 'hire for attitude and train', besides evaluating skills and knowledge.

\section{RECRUITMENT AND SELECTION FLOWCHART}

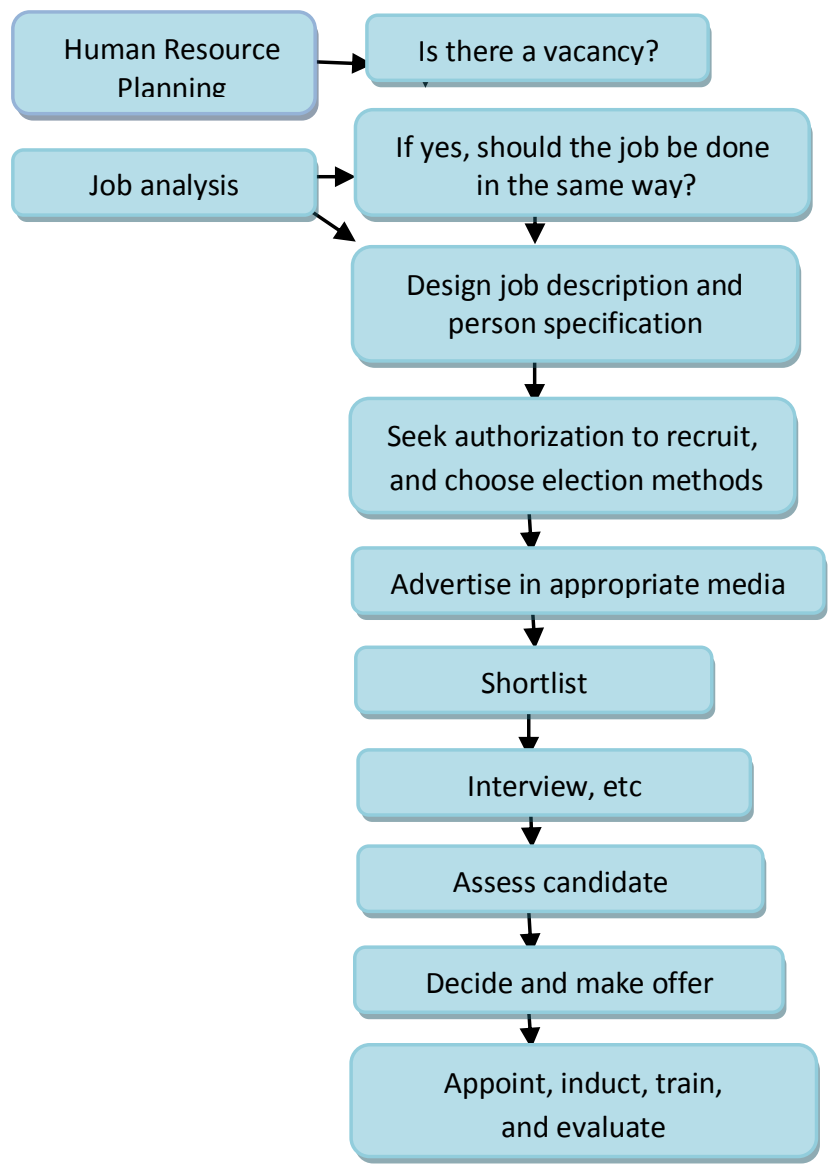

VII. RECRUITERS' EXPECTATIONS APART FROM THE ACADEMIC EXCELLENCE, TECHNICAL EXPERTISE AND DOMAIN KNOWLEDGE 
Apart from the functional skills recruiters look for a host of factors like;
$\checkmark \quad$ Strategic suitability with the organization's vision, values, culture and business direction.
$\checkmark \quad$ Integrity, professionalism and discipline in business conduct.
$\checkmark \quad$ Entrepreneurship and innovation in handling business complexity.
$\checkmark \quad$ Willingness to learn and grow to assume more complex and enhanced future job responsibilities.
$\checkmark \quad$ Leadership and likability.

The three most important aspects of talent acquisition are getting the right hire, nurturing and developing it and then matching its expectation and the gross development. This is what makes selection and recruitment a significant process in an enterprise.

There are three important things that I have noticed what an HR personnel does: he does hatch, match and dispatch; which is to say that the HR hires a person, matches with the organization's expectations and requirements and dispatches the employee as moving on to another company or by retirement.

\section{SOME KEY OPERATIONAL ELEMENTS STRESSED UPON AT THE TIME OF HIRING QUALITY RESOURCES}

$\checkmark \quad$ Wherever possible, making it sure to have a face-to-face interaction with the candidate or an interview through video conferencing.

$\checkmark \quad$ Understanding the job role very thoroughly for which a candidate is to be recruited and have clarity on the functional and behavioral skill requirements. As interviews are conducted along with the line managers,

$\checkmark \quad$ Making it a point to check the line manager's feedback on the functional competencies of the candidate and appropriateness of the job knowledge.

$\checkmark \quad$ Understanding a candidate's value system and see if it complements or contradicts the bank's values.

$\checkmark \quad$ Checking on a candidate's personal ambitions and see if a match is possible, otherwise there is likely to be heart-burn after joining.

\section{Changes In The Pattern Of The Hiring Processes}

\begin{tabular}{|c|c|c|}
\hline Parameter & Traditional Approach & Contemporary Approach \\
\hline Recruitment \& Selection Policies & Standardized & Flexible as per Business Needs \\
\hline Sourcing Base & $\begin{array}{l}\text { Limited - Newspaper Ads, } \\
\text { Consultants, Campus }\end{array}$ & $\begin{array}{l}\text { Diversified - Social Networking } \\
\text { Sites, Job Portals, Web-sites, Employee } \\
\text { Referrals, Internal Job Postings }\end{array}$ \\
\hline Recruiters & Mainly HR Personnel & HR personnel and Line Managers \\
\hline Recruitment Focus & $\begin{array}{l}\text { Short term focus on filling vacant } \\
\text { positions, cost consciousness }\end{array}$ & $\begin{array}{l}\text { Pay premium to poach critical hires, const } \\
\text { consciousness in mass hiring }\end{array}$ \\
\hline Selection Techniques & Interviews, Written Tests & $\begin{array}{l}\text { Competency assessment, Reference checks, } \\
\text { Background verification }\end{array}$ \\
\hline Hiring Decision making & Centralized - Corporate level & $\begin{array}{l}\text { Decentralized to Zones / Regions / Business } \\
\text { Units }\end{array}$ \\
\hline
\end{tabular}

Source Zubin Mody

\section{$X$ STRATEGIES AND APPROACHES}

Talent acquisition is among the most crucial tasks of human resource professionals. A successful recruitment strategy should be well planned and practical to attract good talent.

In order to increase efficiency in hiring and retention and to ensure consistency and compliance in the recruitment and selection process, it is recommended the following steps be followed.

X.I Identifying and prioritizing jobs: Requirements keep arising at various levels simultaneously, so it is impossible to fill all the positions immediately. Therefore, there is a need to identify the positions that require immediate attention and action 
X.II Candidates to target: The recruitment process can be effective only if the recruiter completely understands the requirements of candidates.

X.III Sources of recruitment: Two main sources of recruitment are: internal and external recruitment. Most of them strongly use their employee referral scheme to fill the maximum vacancies, followed by job portals. The senior positions are given on retainer ship basis.

X.IV evaluating candidates: The various parameters to judge them should be planned in advance like a written test, technical knowledge, interviews, HR and behavioral interviews.

\section{FINDINGS}

Software engineers in India, with at least two to three years of experience, are in great demand, thanks to the revival in the fortunes of the Indian IT industry. Rising from the ripple effect of the global recession from 2008 till the middle of 2010 that seemingly impacted hiring of engineers, not only Indian IT sector but also other sectors are now on a massive hiring spree. To the great extent pay packages, allowances and other variable payments too are skyrocketing as companies are vying with each other to hire and retain the best brains.

India has become attracting market for foreign investors as India is emerging as an economic power with 30 million middle class families (approximately) as consumers. India also produces a million engineers which is one of the largest talent pool with English proficiency. Apart from these there are several other developments that make India Centre for Inventions.

IX. I A real time example: (Case Study) TCS recent announcement of annual result (2012 -2013), it is mentioned that TCS has a diverse workforce of 2, 76,196 employees representing 118 nationalities. Human Resource policies and processes have evolved to stay relevant to the changing demographics, enhance organizational agility and remain compliant with the changing regulatory requirements. In financial year 201213, the Company remained the highest recruiter in the industry, with a gross addition of 69,728 and net addition of 37,613 employees across the globe. Campus placement drive was conducted in 371 engineering institutes in India resulting in 24,531 job offers to students to join in the financial year 2013-14. All the students who were given job offer last year were inducted into the organization during financial year 2012-13. Trainees were recruited from established institutes across the globe. The Company continued its effort to strengthen relationship with key institutes globally through its academic interface program which benefited 616 institutes in India and 288 institutes in other countries. Individual and organizational capability building remained one of the strategic focus areas. A total of 12,789 person years of effort were invested in enhancing the proficiency levels of the employees and in developing a steady stream of business leaders ready to take on the challenges as per growing requirements of the organization.

Apart from increased hiring, the turnaround in Indian IT industry is also visible clearly from the financial results of top IT firms in the quarter ending December 2013. Thanks to a general improvement in IT spending by firms in the USA and Europe, the Indian IT companies on the whole are making larger profits, having less pricing pressures and are exploring new areas for faster growth.

As poaching has returned with the growth, IT companies are also working out new plans to meet the challenge of retaining existing workforce.

TCS, according to Mukherjee, has already introduced the system of quarterly promotions of deserving junior employees and from January 2010 has re-introduced the system of two cycles of promotions for the seniors, one in January and the next in July.

Infosys, which has nearly 1, 30,000 employees on its payroll, has already hiked salaries by 17 per cent this year and plans to give another wage hike in the next three months.

Therefore, it is evident that Indian corporate industry has just had slight impact of recession able to revive quickly and greatly doing well in terms of creating good deal of business that leads for great demand of talent pool. Obviously that generates opportunities. Hence recruitment selection process has ample room to play.

\section{IIX. STEPS TO BE CONSIDERED}

1. Recruitment should be seen as an investment and not a cost.

2. Human resource planners/managers must go beyond recruitment and selection process. They must address employees' training and development needs.

3. Communication and co-ordination between line managers and human resource planners could result in identification of training and development needs that exceed current requirements and thereby forecasting the number of personnel that may be required at any given time and this may in turn necessitates recruitment and selection process. 
4. There must be a strong relationship between human resource management and business plans. This focus or paradigm should be reinforced when the company is recruiting and selecting new employees to ensure there is a balance between HR planning and corporate plans.

5. Recruiters should make wise and effective recruitment and selection decision that should guarantee higher levels of employee retention.

6. Recruiters should focus more on cultural fit rather knowledge, skill and competency, because these can be assessed where as the former one is difficult.

7. The workforce management strategy should be executed optimally to deliver a sustained utilization rate throughout the year helping business grow while maintaining employee costs at the desired level.

8. The robust and mature talent management and talent engagement processes have to be incorporated to create an environment where performance is rewarded, opportunities are provided for career growth and people are encouraged to realize their potential.

9. Focused initiatives towards health and safety and other non-work related employee engagement programs may be organized to develop the personality and confidence level of the employees enhancing their motivation and engagement with the organization.

10. There should relentless drive to create One Culture of across the organization that helps the Company in integrating its diverse global talent base into a cohesive high performing unit.

11. The employment conditions of an organization should be flexible coupled with suitable working conditions, good and enticing remuneration packages.

12.Performance Management system - including performance appraisal, improved productivity and competencies should therefore be made integral part of human resource planning.

13. HR practitioners should align organizational values with employees' values upon selection.

14. The organization must put good transition program (succession planning) in place to make recruitment and selection process flawless.

\section{IIIX. CONCLUSION}

The human capital function is the core of an organization that is instrumental and responsible to every facet of work and talent assets who is an integral part of an organization. Evidently, the evolution of H.R functioning has been pivot in the competitive advantage for the organizations. Most of the corporate companies have believed it and utilized their excellence and proficiency in employee matters and surpassed the affect of global recession on Indian companies.

In addition to that Indian recruitment and selection process has brought enormous changes in their trends, strategies and approaches in finding, attracting, recruiting and retaining the potential human capital.

I think, the constant effort of the H.R.M towards innovative approaches, ability to adapt the changing trend, cohesiveness between H.R and other departments (line managers, etc) has contributed a lot to the Indian corporate industry the path of accelerating the growth.

Last but not the least; it is well proved that Recession impact has not been as much as it was pretended on Indian job market. If we notice the Indian IT, ITEs hiring ratio and increased employee strength it's been constantly good, the only drawback in India is that most of the aspirants don't possess the industry required skill set where there is dire need to enhance professional skills among Indian professional students.

\section{REFERENCES}

[1] Armstrong, M (2009), Handbook of HRM practice, Kogan Page, London and Philadelphia

[2] Article published by DECCAN HERALD News paper (11/6/13)

[3] http://www.deccanherald.com/content/133284/it-companies-logging-high-growth.html.

[3] Human Factor Monthly magazine published by IIPM (A PLANMAN MEDIA -IIPM THINK TANK PUBLICATION)

[4] http://www.moneycontrol.com/annual-report/tataconsultancyservices/directors-report/TCS\#TCS

[5] http://businesscasestudies.co.uk/enterprise-rent-a-car/recruitment-and-selection-at-enterprise-rent-acar/introduction.html\#axzz2 Vt4XUXd7

[6] http://hr.ucr.edu/recruitment/guidelines/proces s.html

[7] http://www.slideshare.net/ramanraman/us-recession-and-its-impact-on-indian-economy

[8] http://www.scribd.com/

[9] http://www.dipity.com/

\section{Biographical Sketch}

Corresponding Author: Mr. U. Madhavaiah is an Assistant Professor of English at Vardhaman College of Engineering, Hyderabad, is pursuing external Ph.D. in Communication \& Soft Skills, and has got eight years of Corporate Training \& Teaching experience for employees and professional students across the state of A.P. Mobile: 08019714018. 